\title{
Uma interpretação do Primeiro Milagre Econômico Alemão (1933-1944)
}

\author{
RICARDO LUIS CHAVES FEIJÓ*
}

An interpretation of the First German Economic Miracle. The German Third Reich was successful in reaching its economical objectives. It is intended to explain the causes of the First German Economic Miracle, fitting its economic system into the category of command economy, which does not confuse itself with the centrally planned economy. Thus, in the first section, we describe the so adopted politics in this period and explain how they had led to the recovery of the German economy. The second section evaluates global indicators of economic performance and population welfare. We are looking for to demonstrate the hypothesis that the Nazi economy was efficient. Such efficiency is explained by the characteristics of the German model.

Keywords: Nazi Germany; economic performance; command economy.

JEL Classification: N44.

\section{INTRODUÇÃO}

A economia alemã no Terceiro Reich foi eficiente, e não apenas quanto ao esforço de guerra, mas para manter um nível de consumo civil relativamente satisfatório. Tradicionalmente acredita-se que a economia alemã tenha se orientado para ser uma economia de guerra mesmo em tempo de paz - o período anterior à eclosão do conflito mundial. Na verdade, o oposto ocorreu: foi uma economia de paz em tempo de guerra, pelo menos ainda durante os primeiros anos do conflito.

O objetivo do ensaio consiste em examinar uma ampla fonte de dados sobre a economia alemã do período. Ele examina por meio de quais medidas de política

\footnotetext{
* Professor Livre-Docente (Associado) em dedicação integral à docência e pesquisa, Faculdade de Economia, Administração e Contabilidade de Ribeirão Preto, Universidade de São Paulo. E-mail: riccfeij@ usp.br. Submetido: Agosto 2006; Aprovado: Janeiro 2008.
} 
econômica os números de desempenho puderam ser alcançados. Argumenta-se que o sucesso na recuperação alemã nos anos 1930 deve ser creditado às políticas de corte keynesiano previamente defendidas e que vieram a ser efetivamente adotadas. Ele também se deve a uma engenhosa engenharia financeira que assegurou recursos para a expansão do crédito e investimento estratégico em setores voltados ao consumo popular, em especial ao setor de construção civil. Com a economia nos eixos, novo dinamismo foi assegurado pelo ímpeto da demanda da indústria de armamentos, sem prejuízo para o consumo da população. O artigo procurará demonstrar que a economia alemã saiu-se bem em alcançar seus objetivos, de modo que se pode falar para o período do Terceiro Reich de Milagre Econômico Alemão; ou, para distinguilo do milagre dos anos 1950, de Primeiro Milagre Econômico Alemão.

Pretende-se aqui abordar a temática do Primeiro Milagre Econômico, enquadrando-o em um esquema teórico que identifica um modelo de economia de comando, que não se confunde com a economia centralmente planejada. Assim a primeira seção descreve essa moldura teórica caracterizando o sistema alemão do período pela descrição genérica e atribuição das características principais de um sistema econômico deste tipo. Também mostra as políticas adotadas entre 1933 e 1945 e que levaram à recuperação da economia alemã, depois ao forte rearmamento. Defende a tese de que a eficiência da economia alemã, nas condições enfrentadas pelo país, explica-se pelo tipo de sistema econômico então adotado.

A segunda seção avalia os indicadores globais de desempenho da economia alemã. Analisa-se a evolução do PNB, a oferta de armamentos e munições no contexto do esforço de guerra, a demanda de consumo civil e a ingestão de calorias da população não prisioneira. Procura-se, nesta parte do ensaio, demonstrar a hipótese de que a economia do Terceiro Reich foi eficiente.

\section{EM BUSCA DE UM ENTENDIMENTO TEÓRICO DO SISTEMA ECONÔMICO DO NAZISMO}

Os nazistas não eram a favor da supressão da propriedade privada, na verdade odiavam o ideário comunista mais radical. Eles aceitavam as diferenças de classe social, contudo achavam que as diferentes classes deveriam reconciliar-se umas com as outras por meio da supervisão e do controle do estado. Para tanto, não seria necessário o completo intervencionismo com a abolição da iniciativa privada.

$\mathrm{O}$ projeto econômico nazista priorizava dois eixos: o primeiro deles era o combate ao desemprego. De fato, quando o partido nazista assumiu o poder, em 1933, havia 6 milhões de desempregados, um terço dos trabalhadores. O nível mais alto de desemprego havia sido atingido na primavera de 1932, tendo então se estabilizado neste patamar (Abelshauser, 2000: 123-124). Outra meta prioritária do governo de Hitler era o programa secreto de rearmamento da Alemanha. No entanto, num primeiro momento a meta de criar empregos foi prioritária. 
A tática inicial não implicava uma completa reformulação do sistema econômico herdado da República de Weimar: não ocorreram confiscos ou socialização forçada. Cooptando um número de grandes empresários, o regime priorizou uma política de criação de empregos em programas específicos nesse sentido. Investiu-se em infraestrutura pública, estradas e moradias. As despesas militares permaneceram de importância secundária nos dois primeiros anos de gestão. Os programas de criação de empregos foram financiados pelo Reichsbank, sob a liderança de Schacht.

Algumas medidas de natureza tributária e fiscal foram tomadas. $\mathrm{O}$ crédito ao consumo desempenhou um papel importante no período. A convicção de que a saída da depressão econômica, que se prolongava desde 1928, passava por políticas de estilo keynesiano de expansão da demanda agregada via gastos públicos era compartilhada entre os membros do movimento nazista. Os radicais de direita alemães nutriam uma certa simpatia pelas ideias de John Maynard Keynes. O pensador inglês se popularizara entre eles desde que publicou o livro As consequências econômicas da paz (Keynes, 1991) que denunciava o Tratado de Versalhes, odiado pelo povo e que servia com frequência de mote da mensagem nazista, obcecada em condená-lo como uma traição à pátria. O NSDAP foi o primeiro grande partido a incorporar ideias keynesianas e as promoveram antes mesmo de chegar ao poder. ${ }^{1}$ Nos primeiros anos da crise, o governo conservador de Brüning aplicava políticas deflacionárias clássicas em linha com os economistas socialdemocratas, em especial com a autoridade acadêmica de Rudolf Hilferding. Para eles, programas de criação de empregos eram tidos como inflacionários. Não significa que ainda na República de Weimar não se tivesse implementado alguma iniciativa deste tipo, porém os programas eram tímidos.

Hitler particularmente era avesso a experimentações em economia e preferia a companhia de economistas de estilo conservador. Não obstante, ele não poderia fazer ouvidos de mercador aos membros mais radicais do partido nazista. Tentando conciliar a orientação do partido com suas convicções pessoais, Hitler recusou a alternativa radical do programa de Gregor Strasser (Sofortprogramm) e impôs a sua

\footnotetext{
${ }^{1}$ Esta tese é defendida por Overy (1996) e Abelshauser (2000). A proximidade entre os economistas do partido nazista e as ideias de Keynes começa com a excelente aceitação, por partes daqueles, das ideias contidas no ensaio As consequências econômicas da paz. Mas não param por aí. É bem verdade que a teoria acabada de Keynes somente apareceu em 1936 na ocasião do lançamento da Teoria Geral do emprego, dos juros e da moeda. Contudo, o receituário de Keynes a favor de políticas ativas já era conhecido antes da divulgação desta obra. Llewellyn H. Rockwell Junior (2003) sustenta a mesma posição quando afirma que "Os economistas de Hitler rejeitavam o laissez-faire e admiravam Keynes; até mesmo se anteciparam a ele em diversos sentidos". Curiosamente a recíproca também era verdadeira, o próprio Keynes admirava o programa econômico nazista. Em apoio a esta tese, é suficiente citar uma passagem do prefácio escrito por ele por ocasião da edição alemã da Teoria Geral: "A teoria do produto agregado, que o presente livro intenciona fornecer, é muito mais facilmente adaptada às condições de um estado totalitário do que a mesma teoria da produção e da distribuição do produto sob as condições da livre competição e presença ampla de laissez-faire". Sobre a concordância de economistas keynesianos quanto à política econômica de Hitler, ver o ensaio de George Garvy (1975).
} 
própria orientação com o Programa do NSDAP de Reconstrução Econômica que eliminou os conteúdos mais à esquerda da iniciativa anterior. Em especial, no novo programa percebia-se nitidamente a estratégia de aliança com os grandes grupos empresarias na execução das políticas. A criação de emprego não se daria por meio de políticas fiscais irresponsáveis que onerassem o Tesouro, mas valendo-se da parceria com o Reichsbank que apoiaria os programas de crédito produtivo.

Já em 1933, Hitler pensava em um amálgama entre os programas de criação de emprego e de rearmamento. Ou seja, ele resolveria o problema econômico principal enquanto ampliaria o poder militar da Alemanha. No entanto, ele foi convencido por Schacht e pelo seu ministro do trabalho, Seldte, de que a criação de empregos economicamente úteis teria precedência sobre empregos com ênfase militar. De fato, havia poucos projetos militares com grande efeito na criação de vagas de trabalho.

As mudanças no sistema econômico herdado foram graduais. Ao mesmo tempo em que políticas do receituário keynesiano foram aplicadas a fim de contornar as falhas imputadas às políticas econômicas liberais de até então, a economia caminhava na direção de um grau maior de planificação centralizada. O planejamento da economia fora concebido em torno a três estratégias para o ataque ao desemprego: medidas de expansão do crédito, de incentivos fiscais e políticas específicas de investimento. Do lado do crédito, procurou-se estimular a indústria de bem de consumo e, ao mesmo tempo, incentivar a expansão demográfica. Assim, criou-se mecanismo de empréstimos subsidiados (sem juros) para casamento, para aquisição de móveis e utensílios domésticos a recém-casados etc. Do lado tributário, foram removidos os impostos sobre veículos como um meio de estimular a sua produção. Sobre os investimentos, o financiamento público concentrou-se na construção e manutenção de estradas, na construção de prédios públicos, na indústria de transporte e algo para o rearmamento. Exceto este último item, menos expressivo, as demais iniciativas não tiveram relação com o programa de rearmamento. Os gastos na construção de estradas não tinham valor estratégico para os militares que preferiam investimentos em ferrovias. Além disso, as rotas das modernas autovias em construção eram determinadas apenas por considerações de engenharia sem a interferência das forças armadas. ${ }^{2}$

\footnotetext{
${ }^{2}$ Há os que acreditam que o investimento público durante este período fora escolhido na base de como o investimento poderia ajudar o rearmamento da Alemanha e a colocá-la em um posição favorável para vencer uma guerra. Tais historiadores citam as iniciativas em infraestrutura nas Autobahns, na indústria de caminhões (pelo subsídio para compra de caminhões aos empresários novos), na indústria de carros etc, que segundo eles teriam sido feitas visando à guerra. Esta opinião não é consensual, pelo contrário, eminentes historiadores como K. Ludwig e W. Abelshauser enfatizam o caráter essencialmente não militar dos gastos públicos nos primeiros anos do Terceiro Reich: “ [...] the state job creation programmes put forward by the Nazi régime [...] were not intended to finance rearmament". Sobre o objetivo não militar das Autobahns: "There was no 'strategic co-decision' by the armed forces. Where the War Ministry did raise objections to the route of particularly exposes roads, as in 1935 in
} 
A gestão nazista, de início, começou com mudanças discretas na organização do estado: fundiu ministérios, ampliou áreas de influência de uma burocracia específica a fim de obter a cooperação das demais. A política econômica ortodoxa foi abandonada não apenas por inclinações keynesianas dos nazistas, mas também devido à situação dramática em que o país se encontrava, especialmente quanto ao grau de endividamento externo (Overy, 1996: 16). A retração da economia mundial cortou as exportações alemãs pela metade. Os credores, preocupados, pressionavam pelo pagamento da dívida num quadro em que o país tinha rebaixado sua capacidade de angariar divisas.

O sistema bancário e o mercado de capitais estavam agora sob estreita vigilância e supervisão do estado, porém não foram abolidos. O estado apenas interferia no sistema, sem liquidá-lo, de forma a evitar crises de liquidez e manter o bombeamento de crédito na economia. No mercado de trabalho, o governo impôs o controle dos salários: os salários foram congelados em 1934 e permaneceram fixos até 1945. As centrais sindicais foram abolidas e nenhum mecanismo de barganha coletiva sobreviveu. As greves foram proibidas e todos os trabalhadores, inclusive os de colarinho branco, tiveram que se filiar à organização nazista Frente de Trabalho Alemã, vinculada à Câmara Econômica do Reich: a instância máxima de controle de todas as atividades econômicas.

$\mathrm{Na}$ vida das empresas, elas foram obrigadas a integrarem-se a organizações corporativas dispostas numa hierarquia de controles. Todas as atividades produtivas estavam sob o guarda-chuva da Câmara Econômica do Reich. Cada ramo industrial específico estava organizado em grupos econômicos de filiação compulsória. Estes grupos econômicos, por sua vez, ficavam todos ligados entre si e eram controlados por um organismo maior denominado Grupo Industrial do Reich. As indústrias do mesmo ramo foram unificadas em cartéis compulsórios. Até 1936, foram feitos mais de 1,6 mil acordos de cartel que afetavam mais de $2 / 3$ da indústria. Outros ramos de negócio como comércio, bancos, agricultura etc. ficam sob a jurisdição de um dos grupos do Reich.

Os grupos econômicos estavam submetidos ao Comissário Geral de Preços do Reich, que controlava os preços. A perda de independência econômica com controles e regulação afetava a todos os setores da economia. O estado controlava mercados e preços, ao mesmo tempo em que interferia diretamente nos métodos de produção, encorajando algum tipo de racionalização. Também as relações sociais na produção eram controladas; em especial, as questões trabalhistas, tanto na cidade quanto no meio rural.

A experiência nazista começou substituindo a ênfase liberal da República de Weimar por uma política mais intervencionista de estilo keynesiano. Respeitou-se o modelo de economia mista com mercados, razoável estabilidade monetária e a

relation to the Black Forest highway, it was typically overruled, in this case in order to preserve the route's scenic charm" (Abelshauser, 2000: 127). 
sintonização da economia por meio de políticas fiscais apropriadas. O planejamento no Terceiro Reich não alcançou o grau de centralização e de controle das economias comunistas. Constituía, porém, uma tentativa até então desconhecida nas economias ocidentais de integrar num plano geral as estratégias setoriais de ação econômica. O planejamento da economia fora concebido inicialmente por Reinhardt. Trata-se do assim chamado Primeiro Plano Quadrienal, que se estendeu de 1933 a 1936. Era a fase de criação de emprego da política nazista. O Segundo Plano Quadrienal, de 1937 a 1940, foi comandado pelo plenipotenciário Hermann Göring, um dos líderes nazistas de primeira hora. Nesta segunda fase, o grau de intervenção do estado cresceria, alterando o sistema econômico alemão de uma economia mista keynesiana, para uma economia de comando ou gerenciada ( gelenkte Wirtschaft), sem ser uma economia centralmente planejada.

O Primeiro Plano Quadrienal buscou a retomada do crescimento econômico num quadro de retração do comércio mundial, com queda nos termos de troca da Alemanha com o exterior e diminuição das reservas do país em ouro e moeda estrangeira. Enfrentando este contexto adverso, procurou-se intervir fortemente no setor externo da economia. Estabeleceu-se o monopólio estatal no mercado cambial. Racionando divisas, priorizou-se a importação de alimentos e itens estratégicos para o insipiente esforço de rearmamento. O plano perseguia um modelo de economia autárquica ou autossuficiente. O equilíbrio comercial seria alcançado através da continuação da política de minidesvalorização cambial iniciada no governo de Brüning.

O Primeiro Plano Quadrienal teve como principal protagonista o Reichsbank de Schacht com sua injeção de recursos via financiamentos na economia civil. A reintegração de 6 milhões de desempregados através de investimentos em construção civil e indústria de bens de consumo haveria de ter um impacto sensível na economia. Mesmo com os salários congelados, o aumento da massa salarial com a expansão do emprego acarretou notável crescimento na demanda privada, de modo que já em 1936 a economia alemã começava a sofrer de insuficiência de oferta. $\mathrm{Na}$ avaliação dos líderes nazistas, era necessário intervir ainda mais na economia para frear a expansão da demanda privada e assegurar a expansão do estado na economia alemã com vista à estratégia de preparação para a guerra. $\mathrm{O}$ esforço armamentista passou a ser a tônica do Segundo Plano Quadrienal.

$\mathrm{Na}$ condução do plano, a agência de Göring intensificou os mecanismos de controle já presentes na fase anterior, ao mesmo tempo em que criava novos instrumentos. Manteve-se uma política rígida de controle de preços e de salários, ampliou-se a regulamentação dos investimentos, com proibições, impostos e indicação de prioridades. E também: controle de câmbio, políticas de administração da demanda e de alocação da força de trabalho. Göring perseguia a eficiência da economia no sentido de deixá-la pronta para a guerra em quatro anos. Buscando a substituição de importações, priorizou-se a ampliação de indústrias como petroquímica, óleo sintético, borracha vulcanizada, alumínio, e ainda mineração de 
ferro e siderurgia. Os investimentos se deslocaram da indústria de construção civil e de bens de consumo para os investimentos na indústria de produção de armamentos. O eixo maior de ação consistia em estimular a produção bélica sem prejuízo do padrão de vida alcançado com a recuperação anterior da economia alemã. Para tanto, perseguia reduzir a dependência externa da economia e reformar o sistema regulador.

A maior intervenção do estado na fase de economia de comando levou a uma distorção no padrão de consumo e de comércio internacional. A política econômica favorecia deliberadamente os grupos que viviam do rearmamento e os que se beneficiavam com o fechamento da economia. As perspectivas de ganhos para muitos homens de negócio eram bastante positivas com o envolvimento nas ações do governo. Especialmente em áreas associadas ao esforço armamentista, os lucros cresciam quando favorecidos por contratos com o estado. O governo nazista não sufocou a iniciativa privada e o empreendedorismo nestes grandes negócios. Pelo contrário, estabeleceu-se uma curiosa e complexa relação simbiótica entre governo e setor privado, bem identificada pelo historiador econômico Abelshauser como sendo a privatização da política econômica do estado: os próprios mega-grupos industriais passam a influenciar as decisões do governo, no contexto de um planejamento indicativo, ao mesmo tempo em que o setor privado reconhece e aceita a autoridade estatal.

A gigantesca I. G. Farben controla áreas centrais de planejamento e liderança pessoal do Plano Quadrienal. Também amealhavam grandes negócios empresas como Siemens, Volkswagen, Krupp, Thyssen, Porsche, Gutehoffnungshütte, Rheinmetall etc. Enquanto isso, as indústrias de menor porte do setor de bens de consumo perdiam liberdade. Ohlerdof, economista do Reich, caracterizou a economia nazista de economia de concorrência imperfeita que favorecia grandes firmas (Grunberger, 1970: 124-125). Sua interpretação é correta. Então não se trata de um sistema que suprimiu a propriedade privada, o empreendedorismo e a concorrência. Trata-se, outrossim, de uma economia de comando que promoveu a cartelização da indústria, a fusão de empresas e gigantescos contratos com grandes grupos empresariais, como sustentáculo aos ambiciosos planos de conquista de outros países. A competição era promovida não em nível de pequenas empresas, mas na disputa entre grandes grupos econômicos por uma fatia dos negócios e por influência nas decisões de governo. Não era uma competição apenas de mercado, em que somente critérios de preço e de eficiência deveriam prevalecer, era uma disputa de natureza política em que os contratos eram tecidos com base na competência em posicionar-se na rede de poder do Terceiro Reich.

A responsabilidade pela transformação da economia alemã em uma economia preparada para a guerra foi dividida entre um grande número de agências. A nenhuma delas se impôs uma direção central. O Plano Quadrienal de Göring competia com a economia militar das forças armadas, os ministérios da economia e do trabalho, os comitês locais do partido etc. A competição não se limitava aos grupos 
econômicos disputando esferas de influência no estado. O próprio estado ficava cada vez mais fragmentado, rateado entre feudos de poder comandados por Czares da economia, influentes generais, homens forte do partido nazista e pessoas do círculo pessoal de Hitler. ${ }^{3}$ A fragmentação institucional do controle e das decisões na economia é um fato pacífico. Ela se manifestou tanto na coordenação dos setores da economia civil quanto nos gastos militares.

Os nazistas imaginavam uma guerra de curta duração. Haviam idealizado a estratégia de guerra relâmpago (Blitzkrieg) e a produção de armamentos ocorria em função desta estratégia. Eles desejavam manter uma economia de tempos de paz mesmo em época de guerra. Os gastos com a iniciativa bélica seriam mais do que compensados pelo espólio da conquista de países. Assim sendo, a produção de consumo se manteve no mesmo nível do período de paz (30\% do produto industrial total). A produção de armas e de munições decaiu depois da rápida vitória na França. Apenas o setor de bens de construção civil teve que ceder em prol da produção de armamentos (Gráfico 1).

Gráfico 1: Produção líquida da indústria alemã por ramo industrial (\% do total)

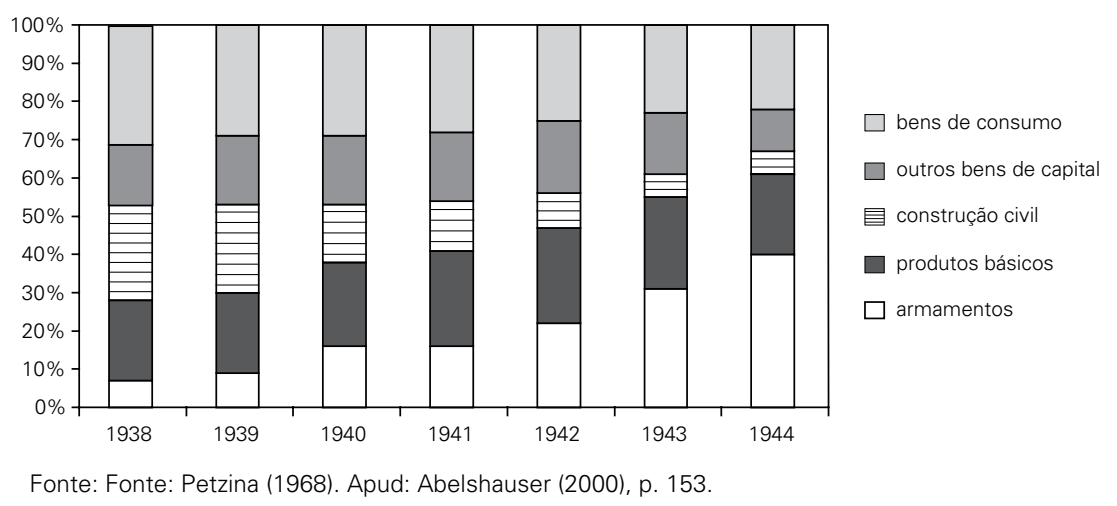

Em 1939, no advento do conflito, a economia de guerra alemã já estava bem avançada, embora o processo não tenha se completado. A Alemanha pode levar o conflito mesmo com a produção industrial total estagnada entre 1939 e 1942 . A pequena queda na oferta de bens de consumo é compensada pelo modesto acréscimo na oferta de bens de produção. A produção para o consumo não cai muito antes de 1942.

Diversos motivos explicam a retomada do crescimento da produção industrial alemã em 1943: importantes projetos iniciados na década anterior ainda não haviam sido completados e passam então a contribuir para a oferta industrial; uma nova estrutura organizacional para a produção de guerra com menor rivalidade

\footnotetext{
${ }^{3}$ Ver a curiosa analogia histórica, sugerida por Grunberger (1970: 105), entre os impérios de Carlos Magno (Primeiro Reich) e o de Hitler.
} 
entre grupos produtores; ênfase na indústria privada etc. Para melhor coordenar as ações dos empresários, Speer reformula em fevereiro de 1942 o Ministério de Armamento e Munição, criado dois anos antes, mas até então pouco operante. Speer assume gradualmente o controle de todas as agências ligadas à economia. Ele racionaliza as cadeias de comando na demanda por armas e elimina as piores deficiências técnicas e organizacionais anteriores. A produção é concentrada nas firmas mais eficientes.

Como resultado desta maior racionalização na produção de armamentos, o setor conhece um aumento de produtividade constante, de modo que em 1944 ela é o dobro do que tinha sido em 1941. No entanto, outros ramos não tiveram ganhos expressivos em produtividade (Gráfico 2).

Gráfico 2: Produção por trabalhador na indústria alemã (\% de 1939)

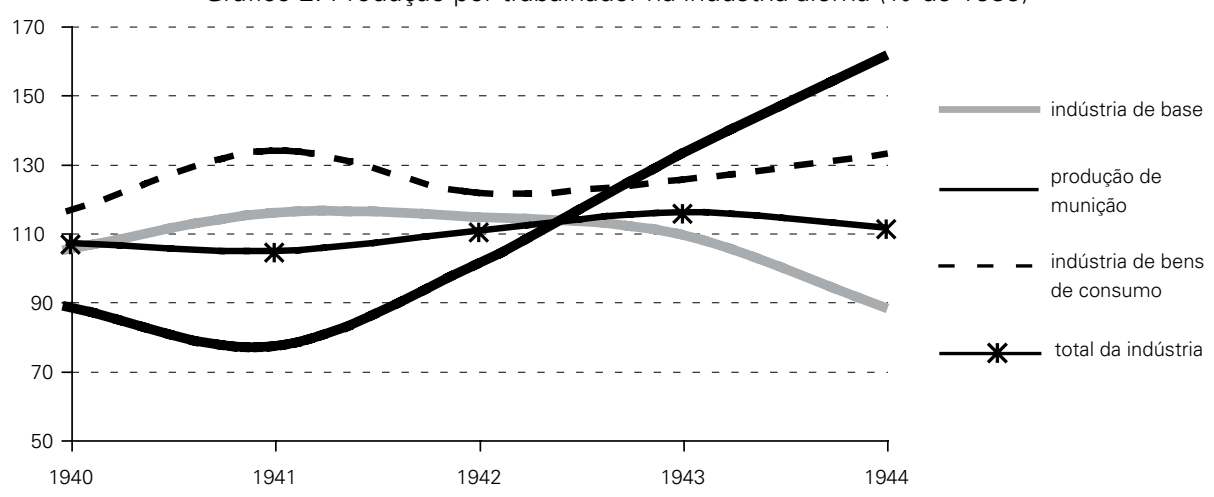

Fonte: Eichholtz (1985). Apud: Abelshauser (2000), p. 155.

Um dos principais feitos de Albert Speer foi introduzir o uso mais racional da força de trabalho, na época em que a Alemanha dispunha de um contingente de trabalhadores com uma composição bastante heterogênea. Speer avaliou corretamente que o recurso mais escasso no esforço de produção industrial alemã era o trabalho qualificado. Havia grande contingente de 4,5 milhões de trabalhadores escravos e estrangeiros, a maioria de baixa qualificação, que estavam alocados principalmente nos setores de agricultura e de transporte. Speer pensou em empregar um maior volume de trabalho forçado e de estrangeiros menos qualificados na indústria. No entanto, isto só seria possível com a simplificação de métodos. Como efeito das medidas de simplificação e da transferência de trabalho forçado e menos qualificado, que puderam ser mais bem aproveitados na indústria, o número de trabalhadores nesta condição, atuando nela, cresceu de 965 mil em 1941 para mais de 3.100 mil em 1944 (Gráfico 3).

Speer percebeu que as grandes indústrias seriam mais eficientes se elas passassem a administrar a si mesmas sem o controle excessivo do estado. Ele percebia a importância do empresário empreendedor e valorizava a liderança carismática de 
Gráfico 3: Tamanho e composição da força de trabalho civil na Alemanha por ramo industrial. Fronteiras pré-guerra. Trabalho forçado e estrangeiros. Em milhares de trabalhadores
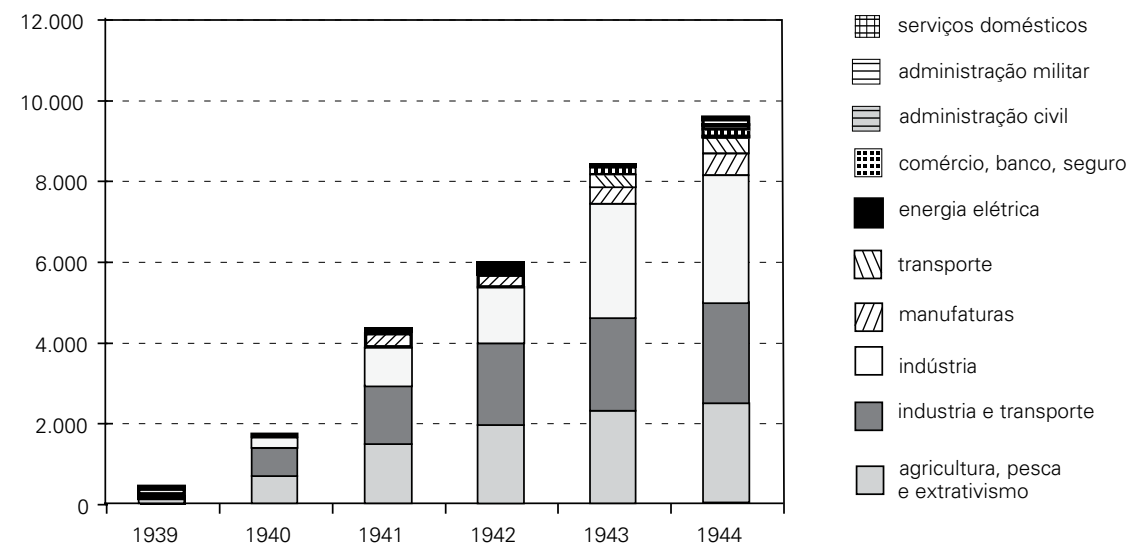

Fonte: Abelshauser (2000), p. 161

grandes empresários na indústria de armamentos. Passou a priorizar a promoção de agentes com formação científica, especialmente em engenharia e contabilidade. As empresas, mesmo as pequenas, tinham de bancar programas de treinamento compulsórios.

Esta exposição sumária da organização econômica do Terceiro Reich, e de sua evolução entre 1933 e 1944, permite agora que se tente entender teoricamente a natureza do sistema econômica na época do nazismo. Há uma afirmação do eminente historiador deste período da história alemã, Trevor-Roper, que vale a pena assinar. Escreve ele:

"É preciso reconhecer [...] que o estado nazista não era absolutamente totalitário (no sentido corrente da expressão), e que seus dirigentes não constituíam um governo, mas uma corte, tão desprovida do poder de ação, mas também tão cheia de intrigas quanto a corte de um sultanato oriental” (Trevor-Roper, s.d.: 61).

A ideologia nazista certamente é totalitária, como o é a ideologia comunista. No entanto, apenas estes últimos aplicaram o totalitarismo na construção de uma administração econômica centralizada, abolindo quase completamente a propriedade privada e submetendo o sistema econômico a um planejamento totalitário. A Alemanha hitlerista não alcançou o modelo de um estado completamente integrado e centralizado. Nem a mobilização da guerra levou o regime a concentrar todos os esforços na obtenção de uma vitória no conflito. Muitas atividades industriais voltadas ao consumo civil continuaram a existir, até mesmo artigos de luxo continuavam a ser produzidos. Diferentemente do regime soviético, no caso alemão a produção, a alocação da força de trabalho, a busca de informações econômicas, a 
administração, nada disso esteve completamente centralizado. As informações eram fornecidas por diversos organismos rivais entre si.

Como caracterizar teoricamente o sistema econômico nazista? Qual o grau de eficiência deste sistema? Estas são questões que até hoje aguardam uma solução teórica que dê conta de explicar os dados empíricos. Trevor-Roper fornece alguma pista quando compara a administração nazista a um "sultanato oriental”. De fato, o regime de Hitler combinava mecanismos de mercado, nos quais os bens eram produzidos e vendidos em atenção a um cálculo econômico e um sistema de preços, com um mecanismo de acesso a bens pelo confisco, pilhagem ou simplesmente roubo. Ele não se configura uma administração descentralizada, caracterizando-se mais no jogo de intriga entre figurões e no poder central certamente brutal, mas de ação frouxa, permeável, procurando mais se posicionar no imenso jogo de intrigas entre os poderosos do que em resolvê-lo num sistema centralizado de poder com hierarquia rígida e comando central da economia.

O nazismo seguiu o receituário de economias mistas que caminham na direção do autoritarismo político e do forte intervencionismo econômico. A aplicação do keynesianismo foi apenas o primeiro passo, depois veio o processo de cartelização da economia, a fusão forçada de empresas, o controle dos mercados, de preços e de salários, o fim dos sindicatos, a supervisão estrita dos pequenos negócios e da agricultura, e por fim uma associação entre o grande capital industrial e a burocracia do planejamento estatal na condução da economia com duplo propósito: prepará-la para a guerra e conduzi-la quando da sua eclosão; manter o consumo civil em nível adequado a fim de assegurar a sustentação do regime.

O sistema econômico adotado pelos nazistas conjugava aspectos aparentemente contraditórios: uma economia com elevado grau de planejamento estatal, com controle dos negócios privados e forte intervenção no sistema de preços e de salários; ao mesmo tempo, uma economia que apresentava um poder central frouxo, que não conseguia submetê-la totalmente aos ditames do centralismo econômico. Então havia certamente um grau maior de descentralização econômica na Alemanha de Hitler do que nos sistemas econômicos socialistas.

A economia parcialmente descentralizada do Terceiro Reich esteve longe do modelo de uma economia clássica de mercado na qual a eficiência é alcançada pela ação do sistema livre de preços. ${ }^{4}$ É evidente que o mecanismo de mercado, orientado pela sinalização dos preços, não pode funcionar muito bem no sistema econômico com preços controlados. Não se pode alcançar grande eficiência pela ação do mercado em um sistema relativamente centralizado como o foi o alemão na época do poder nazista. Então cabe investigar por que o afrouxamento hierárquico do sistema econômico acabou resultando em certa eficiência econômica no caso alemão.

\footnotetext{
${ }^{4}$ Por exemplo, não se pode realizar uma alocação eficiente da mão-de-obra se a variável salário que determina a alocação está fixada como na Alemanha desde período.
} 
Uma diferença importante entre a economia de comando germânica e os sistemas econômicos socialistas consiste no fato de o primeiro manter boa parte dos meios de produção na esfera privada: não ocorreu a coletivização forçada do comunismo. Isto trouxe implicações para o funcionamento do sistema econômico. $\mathrm{Na}$ Alemanha nazista, preservou-se um relativo grau de autonomia para as lideranças empresarias em seus campos de atuação. Com isso o sistema de incentivos à eficiência na produção operou de modo mais eficaz. É claro que mesmo nas economias mais centralizadas concede-se às lideranças setoriais uma relativa liberdade na escolha de método de trabalho e de produção. No entanto, neste caso o gerente de fábrica opera sob o influxo das metas de produção ditadas de fora, e persegueas visando recompensas, sempre que as metas tenham sido alcançadas, e evitando as punições, caso não sejam cumpridas. O mecanismo de incentivos no caso alemão era diferente por se tratar de propriedade privada dos meios de produção. A mudança na natureza da propriedade altera os incentivos aos agentes por dois motivos: quando se é proprietário do capital o que está em jogo é a prosperidade ou a falência do negócio: no limite, lucros extraordinários ou prejuízos insuportáveis. Não se trata tão-somente de agradar ao chefe, burocrata das engrenagens do Estado, mas de manter-se bem no negócio. O sistema de incentivos é melhor quando viceja a propriedade privada.

Outra razão para a maior eficiência obtida pelo modelo nazista então adotado, maior do que seria possível alcançar com a completa centralização econômica, refere-se ao mecanismo de atuação das metas de produção. Tais metas, no caso do comunismo, representam parâmetros nos quais todo o processo de produção nas unidades isoladas procura adaptar-se, sob pena de bloquear a harmonia da produção em seu conjunto, na relação entre todas as unidades produtivas. No nazismo, as metas de produção eram exclusivamente indicativas. A agência de planejamento raramente interferia na ação dos empresários com o intuito de forçar o cumprimento das metas. Mesmo que um determinado setor deixasse a desejar, os burocratas do estado nazista preferiam amiúde uma atitude de entendimento negociado com os empresários a uma ação mais hostil; principalmente em se tratando dos grandes grupos empresarias, até porque estes mesmos haviam apoiado, desde o início, o regime nazista e continuavam a servir-lhe e a se beneficiarem dele, em que pese algumas dissidências de empresários. Com efeito, mesmo que vigiadas e impedidas de atuarem livremente, as forças de mercado, principalmente as perspectivas de lucros empresariais, continuavam sendo um fator a afetar a quantidade produzida, não dependendo ela exclusivamente das metas de produção.

Não se pretende com isso negar que as economias centralmente planejadas também não possam ser eficientes ao seu modo. Os sistemas socialistas centralizados apresentam altíssimas taxas de crescimento econômico durante os primeiros 15 a 20 anos de implantação, depois o ímpeto se arrefece, principalmente pelos problemas de falta de incentivos e de estagnação tecnológica. A tese que se quer demonstrar é a de que o regime nazista, mesmo não perseguindo o modelo de 
centralização comunista e sendo parcialmente descentralizado, também foi eficiente. Ele não teria como adotar o outro modelo, que inclusive estava fora do ideário nazista. Contudo, o sistema econômico de Hitler foi mais eficiente que o planejamento socialista por conseguir manter um bom desempenho simultaneamente na produção militar e civil, ao contrário do sistema soviético que impôs enormes sacrifícios à produção civil às expensas da prioridade do esforço de guerra (ver próxima seção).

Historiadores como Richard Overy e Trevor-Roper enfatizam a ineficiência do sistema alemão por conta do caos aparente na hierarquia de comando, da inexistência de um planejamento efetivo e de falta de centralização nas decisões. O que tradicionalmente tem sido visto como um fator de desvantagem do sistema econômico nazista, a explicar inclusive a sua derrocada na guerra, hoje em dia começa a ser visto com outros olhos.

Aceita provisoriamente a tese, a ser demonstrada, de que a economia alemã comportou-se bem nos moldes do sistema nazista, compreender teoricamente o porquê desta eficiência ajuda-nos inclusive a entender a natureza desse sistema. Para Trevor-Roper, se a Alemanha tivesse implantado a centralização econômica poderia ter vencido a guerra graças às vantagens de seus recursos, seus preparativos e o grau de avanço tecnológico. Contudo, não se pode garantir que a economia alemã teria sido mais eficiente sob a égide do planejamento centralizado.

Os Planos Quadrienais de Göring não tinham nenhuma pretensão e nem condições técnicas e políticas de comandar centralmente todo o processo econômico. Então os grandes empresários estavam livres para agir como desejassem em suas áreas de influência. Estiveram em ação, portanto, a competência do homem de negócio, o processo de negociação essencialmente capitalista e a operação dos mercados, ainda que controlados; todos esses elementos estiveram presentes graças à descentralização e à fragmentação da esfera administrativa do regime nazista. Ora, se havia muitos canais paralelos de informações, como denuncia Trevor-Roper, isto não significa necessariamente ineficiência informacional.

O sistema de produção nazista deixou frouxo o controle sobre os empresários. Isso em nada enfraqueceu sua economia, pelo contrário, a relativa liberdade conferida aos magnatas dos negócios favoreceu a economia. Os grandes empresários agiam em estreita associação com o estado alemão. Com efeito, o estado estimulou por meio de seus altos representantes, como Speer, a racionalização do processo produtivo e o treinamento de parte da mão-de-obra. Mesmo a desvantagem do viés autárquico da política econômica foi parcialmente compensada pelo movimento expansivo e integrador da guerra com suas conquistas territoriais. O Gráfico 4 representa as fontes de recursos financeiros extraídos, ano a ano, dos países ocupados. Nota-se que a França, a Holanda, e em 1944 a Itália, respondem por boa parte dos recursos ganhos com a guerra pela economia alemã.

Em síntese, foi o caráter relativamente descentralizado do sistema alemão que conferiu eficiência ao funcionamento de sua economia civil e de guerra em todo o 
Gráfico 4: Fontes externas de recursos financeiros para a Alemanha.

Custos de ocupação pagos à Alemanha, por região, em bilhões de Reichsmarks

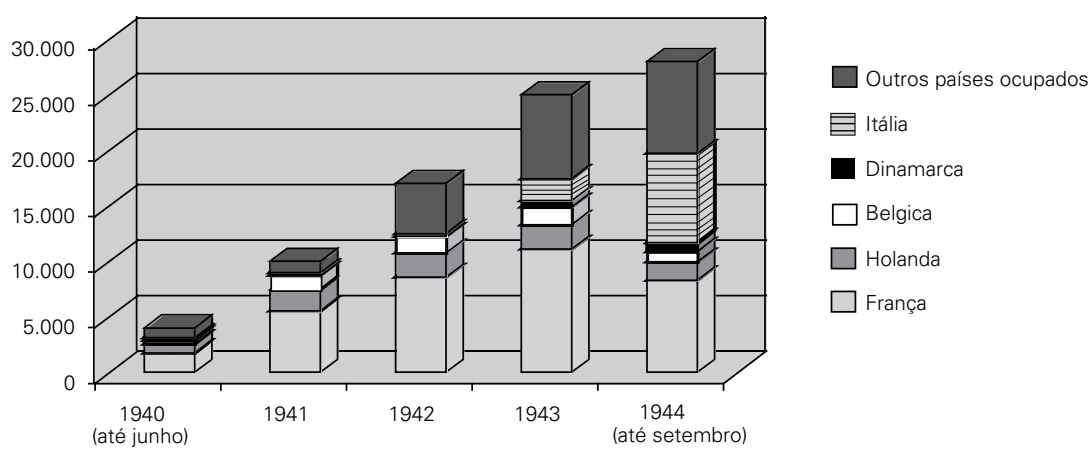

Fonte: Abelshauser (2000), p. 143.

período do Terceiro Reich. Por trás do caos aparente da economia alemã no período, tão denunciado pelos historiadores, havia uma poderosa máquina de produção civil e de guerra. A despeito de seus métodos brutais e desumanos que desgastavam a força de trabalho parcialmente escravizada, havia um sistema produtivo poderoso. Do ponto de vista de maximizar a produção de canhão e manteiga, dadas as restrições do ambiente em questão, o sistema parcialmente descentralizado da Alemanha nazista saiu-se muito bem.

\section{A DEMONSTRAÇÃO DA EFICIÊNCIA DA ECONOMIA ALEMÃ DO TERCEIRO REICH}

A eficiência da economia alemã na gestão nazista pode ser comprovada pela análise dos números indicativos do despenho desta economia no período. Acompanhando-se a evolução global da economia alemã por meio da curva do PNB per capita, partindo do decréscimo econômico no período imediatamente anterior ao início do domínio nazista, nota-se desde então um crescimento contínuo até o ano de 1944 durante o qual a economia quase duplica de tamanho: um êxito notável. Apenas em 1945 e 1946, o PNB alemão desmorona, reduzindo-se no final do biênio para menos de 60\% do pico anterior (Abelshauser, 2000: 124).

Cabe também chamar a atenção de que a ênfase que se confere à política armamentista na recuperação da economia alemã nos anos 1930 tem sido exagerada. $\mathrm{Na}$ literatura especializada, não há uma estimativa única do nível exato dos gastos alemães com o rearmamento até o início da Segunda Guerra Mundial. Abelshauser (2000: 134-135) baseia-se num minucioso levantamento que percorre as estimativas de gastos militares feitas por 13 autores e dois relatórios, incluindo dados fornecidos por Schacht. Tomando-se uma média destas estimativas, teriam sido gastos na Alemanha, em termos acumulados, algo como pouco mais de 70 bilhões de Reichsmarks (equivalente ao PNB alemão de 1931). O Gráfico 5 mostra a evo- 
lução anual dos gastos militares alemães de 1932 a 1938 e também a proporção deles em relação ao investimento público civil.

Os gastos militares começam a ter uma proporção alarmante do orçamento público a partir de 1936, quando a economia alemã já se havia recuperado da crise e também quando se inicia o Segundo Plano Quadrienal sob a liderança de Göring. Mesmo neste período, a expansão dos gastos militares não comprometeu os programas em infra-estrutura e outros investimentos. $\mathrm{Na}$ verdade, o financiamento do rearmamento ocorreu criando-se uma capacidade ampliada de arrecadação de recursos, recorrendo ao mercado financeiro. Schacht, ao assumir a presidência do banco central, criou várias técnicas de financiamento. Era preciso manter o segredo das operações financeiras na criação de um fundo para o esforço armamentista. As potências ocidentais não poderiam desconfiar que os alemães estavam drenando recursos para o rearmamento.

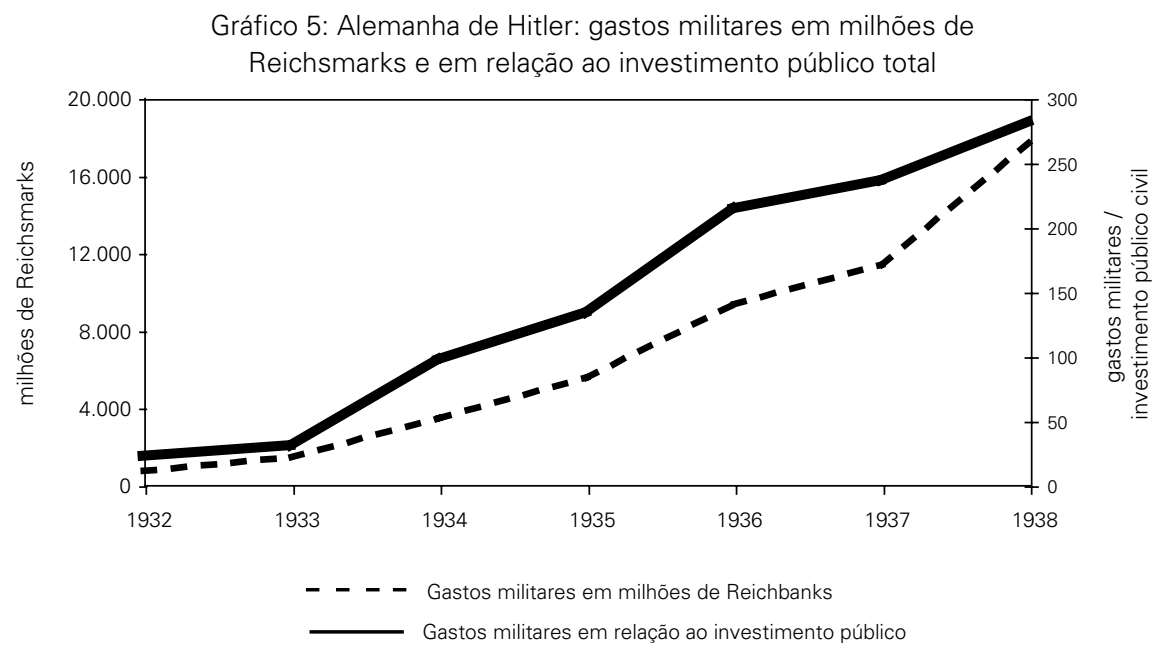

Fonte - Gastos militares totais: cálculo do autor. Valores médios consultando-se 15 fontes.

Apud. Abelshauser (2000), pp. 134-135.

Em relação ao investimento público: Petzina (1977). Apud. Abelhauser (2000), p. 138.

Schacht elabora mecanismos para colocar títulos públicos no mercado sem que os próprios credores soubessem que se tratavam de papéis do governo. O presidente do Reichsbank cria manobras de camuflagem que só foram possíveis por se tratar de um regime ditatorial com poder de encobrir os reais mecanismos financeiros. A manobra mais famosa foi a introdução de um título com boa liquidez, que poderia ser descontado no Reichsbank, denominado Mefo (Metallurgische Forschungsgesellschaft $\mathrm{mbH}$ ). O título Mefo poderia ser trocado por dinheiro no Reichsbank, mas ele também era intercambiável por outros papéis. Assim, o governo preferia vender os papéis a agências de dinheiro e de capital em vez de negociá-los diretamente com o público. A agência captava recursos da poupança popular e da previdência social, e emitia títulos de médio e de longo prazos. Os recursos 
amealhados pelo público e aplicados nas agências eram por elas repassados ao governo em troca de títulos Mefo. Entre 1935 e 1938, o Reichsbank conseguiu colocar no mercado 12 bilhões de Reichsmarks em títulos públicos. Contudo, os aplicadores não sabiam que estavam emprestando ao governo e, com efeito, financiando a aquisição alucinada de artefatos militares. E nem os países ocidentais puderam detectar o mecanismo.

Eram evidentes as vantagens técnicas e políticas destas manobras de Schacht: os poupadores eram credores do Reich e não sabiam; o financiamento para a escalada armamentista corria sem sacrificar os programas da economia de paz, sem muito aumento de impostos, sem gerar inflação e mantendo-se a confiança do público na seriedade do Reichsbank. Cabe uma avaliação do impacto do endividamento do período na evolução do orçamento público alemão: estimativas de future tax burden e do impacto inflacionário e no crescimento da economia. Uma análise mais ampla demandaria espaço de que não dispomos no ensaio, contudo, cabe notar que a dívida fiscal cresceu três vezes, de 13,9 bilhões de Reichsmarks no biênio 1933-1934 para 41,7 bilhões em 1938-1939. Como porcentagem do PNB nominal o crescimento foi menor: dobrou de $16 \%$ para $32 \%$. Mesmo um endividamento de $32 \%$ do PNB é facilmente administrado para os padrões de uma economia vigorosa e em expansão. Ademais, quase $60 \%$ da dívida compunham-se de títulos de médio e de longo prazos. O endividamento torna-se descontrolado apenas no período da guerra: a dívida sobe a quase 90 bilhões de Reichsmarks em março de 1941 e explode em 373,5 bilhões em março de 1945, quase no fim do conflito. O perfil do endividamento também piora: os títulos de médio e longo prazos passam a ocupar apenas 37,5\% das obrigações (Overy, 1996: 132). Não se pode imputar às emissões de títulos Mefo o descontrole da dívida no período da guerra. Nos anos de conflito, os esquemas de capitação de dívidas deram-se de outra forma: junto a grandes grupos financeiros e empresariais ou pelo empréstimo compulsório do público. A avaliação do impacto da dívida pública associada às emissões Mefo é positiva pelo perfil do endividamento até 1939 e por ter mantido a inflação sob controle: em quatro anos a inflação (índice de custo de vida) aumentou apenas 3,4\% (Overy, 1996: 125), mesmo com forte crescimento econômico.

O Gráfico 6 relata a evolução da produção de armamento e munições na Alemanha. Trata-se de uma média mensal de produção tomando-se a média mensal do primeiro bimestre de 1942 como sendo 100. A produção bélica estava condicionada às perspectivas da guerra. A queda da produção mensal entre 1940 e 1941 explica-se pelos rápidos sucessos obtidos com a Blitzkrieg: na época tinha-se a impressão de que os aliados pediriam um armistício e o Reich se consolidaria com tranquilidade nas áreas até então conquistadas. O esforço de produção em 1942 está associado ao alerta emitido pela primeira derrota séria da Wehrmacht na batalha de Moscou.

A produção bélica expandiu-se consideravelmente entre 1941 e 1942, e mais surpreendente, manteve uma forte expansão entre este ano e 1943. O bom desem- 
penho em 1942 pode-se creditar às reformas de Speer que aumentaram a produtividade do trabalhador na indústria bélica. O esforço de produção de armamentos do sistema econômico nazista foi realmente notável. Até praticamente o último mês do conflito, milhares de tanques, aviões etc. eram produzidos nas fábricas transferidas para abrigos subterrâneos a despeito da escassez de matéria-prima. ${ }^{5}$

Gráfico 6: Produção de armamentos e munições na Alemanha, média mensal (jan.-fev. $1942=100$ )

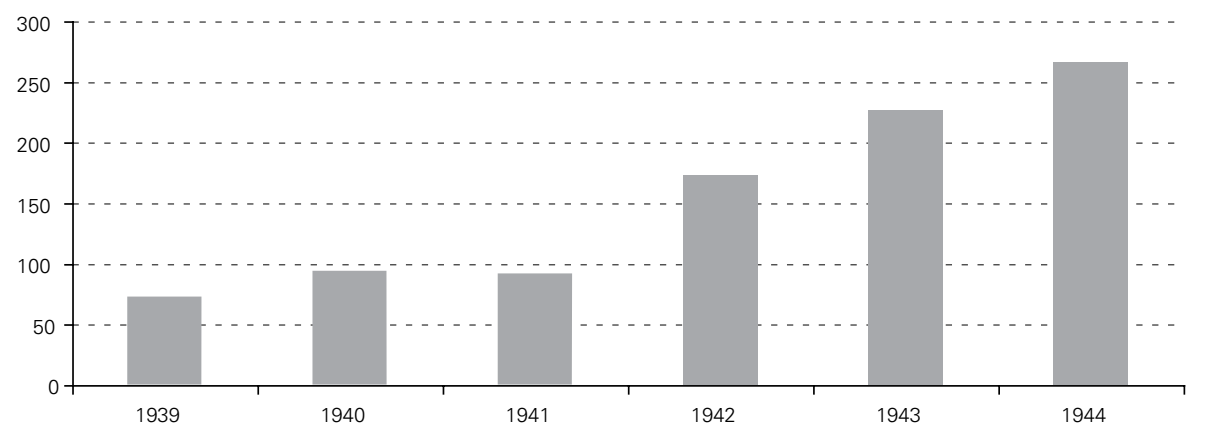

Fonte: cálculos do autor. Apud. Abelshauser (2000), p. 152.

Examina-se agora o desempenho deste sistema econômico no que tange à produção civil. Dois indicadores são apresentados no Gráfico 7: as vendas per capita no varejo como porcentagem de 1938 e o consumo calórico médio de cada membro da família do trabalhador alemão. O poder calórico da dieta do alemão era de 2,5 mil calorias diárias nos dois primeiros anos do conflito. Verifica-se uma queda para o patamar de 2 mil calorias em 1941. Trata-se do efeito da adaptação aos primeiros anos da guerra. Nota-se que depois, até 1944, a despeito das agruras da Alemanha e das derrotas militares, a ração diária mantém-se acima de 1,6 mil calorias. As vendas per capita no varejo também conhecem uma queda no primeiro ano da guerra, mas elas se estabilizam, e mesmo em 1944, já na eminência da derrota, tais vendas se mantêm em pelo menos $70 \%$ do nível de 1938. Então estes dois dados permitem concluir que o sistema econômico do Terceiro Reich logrou manter um razoável nível de bem-estar da população alemã, mesmo em tempo de guerra.

Pode-se questionar se 1.600 calorias de conteúdo calórico das rações para um membro da família do trabalhador atende de maneira satisfatória às necessidades diárias de uma pessoa. De fato, em termos absolutos essas calorias diárias não

\footnotetext{
${ }^{5}$ A escassez de matéria-prima era compensada pelo uso alternativo de materiais não convencionais. Por exemplo, estruturas de madeiras leves e resistentes nos aviões, no lugar de ligas especiais de alumínio; uso de extratos vegetais no lugar de óleos sintéticos derivados do petróleo etc. Uma análise completa do esforço de produção bélica levaria em conta o efeito dos bombardeios, que nos últimos anos da guerra vinham destruindo uma parte do parque industrial alemão, além de afetarem as vias de comunicação, as instalações etc. Um survey completo do impacto destrutivo das bombas aparece em United States Strategic Bombing Survey (1945).
} 
asseguram um nível de bem-estar muito bom associado à alimentação. Contudo, deve-se levar em conta o feito da economia alemã no contexto da guerra. Tomandose como base de comparação o consumo per capita da época para a nação mais rica do planeta, os Estados Unidos, cuja produção agrícola não foi significativamente afetada pelo esforço de guerra, ${ }^{6}$ verifica-se a absorção de 3.340 calorias per capita para a população civil, com pouquíssima variação nos anos de conflito (Rockoff, 2000: 93). É verdade que na Alemanha, no mesmo período, o consumo de calorias foi bem menor. A Alemanha entra no conflito com um consumo per capita da população trabalhadora (índice menor do que o consumo por pessoal civil que inclui empresários e segmentos mais ricos da população) de $70 \%$ do consumo civil nos Estado Unidos, ou seja, de 2.435 calorias (Abelshauser, 2000: 155). Esse percentual cai para 50\% com a economia alemã bastante comprometida em 1944. Nada mal em se tratando se uma economia quase cercada pelas forças inimigas e com seu território retaliado pelo efeito dos bombardeios incessantes. Para se ter uma ideia, a Itália, que se retirou da guerra em 1942, permanecendo apenas a sua parte norte sob os tentáculos dos nazistas, mesmo com subvenções dos aliados, sua população consumia, em média, em 1944, apenas $56 \%$ do consumo de calorias per capita da população civil dos Estados Unidos (Zamagni, 2000: 191), um pouco mais que o trabalhador alemão no mesmo ano.

Gráfico 7: Vendas per capita no varejo na Alemanha (\% de 1938) e conteúdo calórico das rações para um membro da família do trabalhador

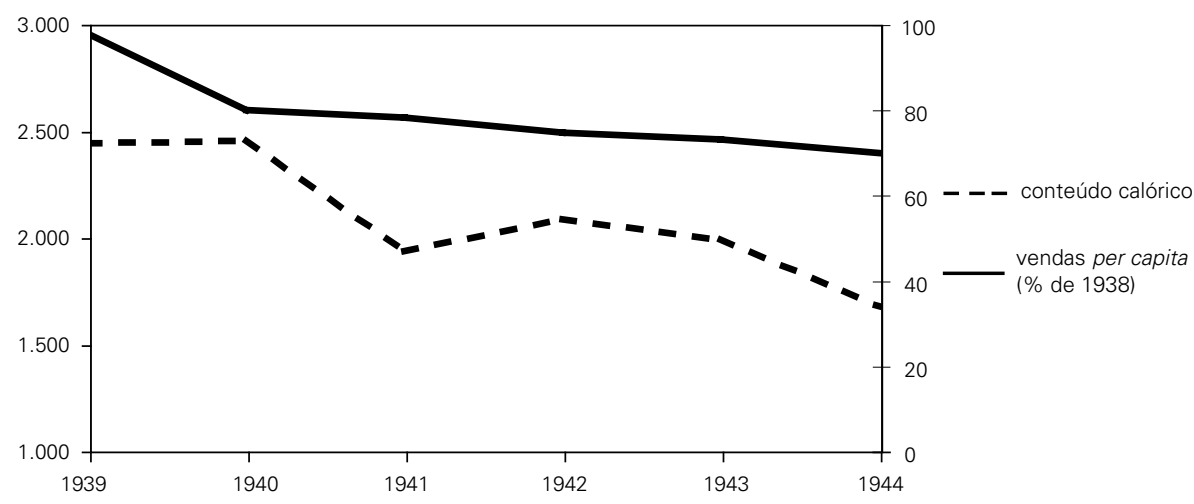

Fonte: Abelshauser (2000), pp. 154-155.

Não se pode negar, portanto, que o sistema econômico alemã tenha sido bem sucedido em um item em que a maioria dos sistemas centralmente planejados falha em oferecer: alimentos para a população. Antes da guerra, em 1937 comparativa-

\footnotetext{
${ }^{6}$ Exceto pela menor produção de fertilizantes nitrogenados, pois esse elemento químico era empregado na produção de munição.
} 
mente a 1927, auge da recuperação alemã dos anos 1920, o consumo de uma cesta representativa de alimentos recupera $90 \%$ do nível alcançado neste ano: o quantum de consumo da classe trabalhadora, para uma cesta contendo pão (de trigo e de centeio), carne e derivados, bacon, queijo, peixe, vegetais, batatas e açúcar, e ainda, leite e ovos, atinge em 1937 uma média apenas 10\% inferior à de 1927. Em certos itens, verifica-se aumento no consumo: pão de centeio (20,2\%), queijo $(11,5 \%)$ e batata $(4,1 \%)$ (Overy, 1996: 127$){ }^{7}$

Pode-se argumentar que o sucesso do sistema econômico alemão em manter sua população razoavelmente alimentada, mesmo no período da guerra, deve-se às requisições feitas aos países conquistados que, de fato, eram obrigados a enviar alimentos para o Reich. A contribuição da França foi importante, embora esse país ainda mantivesse sua própria população em condições mínimas de consumo de alimentos. Exagera-se na interpretação do que representou essa remeça de alimentos oriundos dos países ocupados; em especial, a contribuição da URSS, tida por Hitler como o celeiro da Alemanha, foi bastante modesta, quase irrisória em termos líquidos: a contribuição líquida desse país na oferta de alimentos para o Reich alemão (excluindo-se gasto com as forças armadas atuando na URSS e consumo do pessoal da administração civil nesse país) foi de apenas 1,7 milhão de toneladas de grãos, somando-se tudo o que foi transferido nos anos de ocupação de 1941 a 1944, além de um modesto destaque em itens como carne, manteiga, açúcar e batata. Em média, menos de $10 \%$ da produção soviética era exportada para o territorial original do Reich (Overy, 1996: 129).

O período da guerra não acarretou o descontrole da inflação. O custo de vida para a família alemã (de cinco membros) aumentou apenas 13\% entre 1939 e 1944. O Gráfico 8 apresenta a evolução desse custo de vida no período em questão como porcentagem de 1938. Deve-se notar inicialmente que vários preços estavam sendo controlados pelo governo e que processos de cotas compulsórias de consumo substituíam o mecanismo tradicional de racionamento, via preços, exercido pelo mercado. Os preços de habitação e energia doméstica permaneceram estáveis no período. As maiores pressões inflacionárias ocorriam em itens como alimentação e vestuário. A última classe de bens tinha a oferta consideravelmente reforçada pelo confisco da produção dos países ocupados. O caso da produção têxtil francesa é bem conhecido: com a aplicação das convenções de armistício, os alemães passaram a ter o direito de exigir a entrega de uma certa quantidade de matérias-primas por eles escolhidas, de preferência entre as mais raras e mais caras: lã, couro, seda etc. (Veillon, 2004: 74).

Demonstrar a eficiência no funcionamento de um sistema econômico é sempre uma questão relativa. O que se procurou aqui foi arrolar um conjunto de provas que mostram certa eficiência da economia alemã no período a partir de

\footnotetext{
${ }^{7}$ Ajustado pelas mudanças no poder de compra e tamanho das famílias. Inclui o orçamento de famílias de servos civis com baixa remuneração e salário dos trabalhadores.
} 
Gráfico 8: Custo de vida para a família alemã, \% de 1938

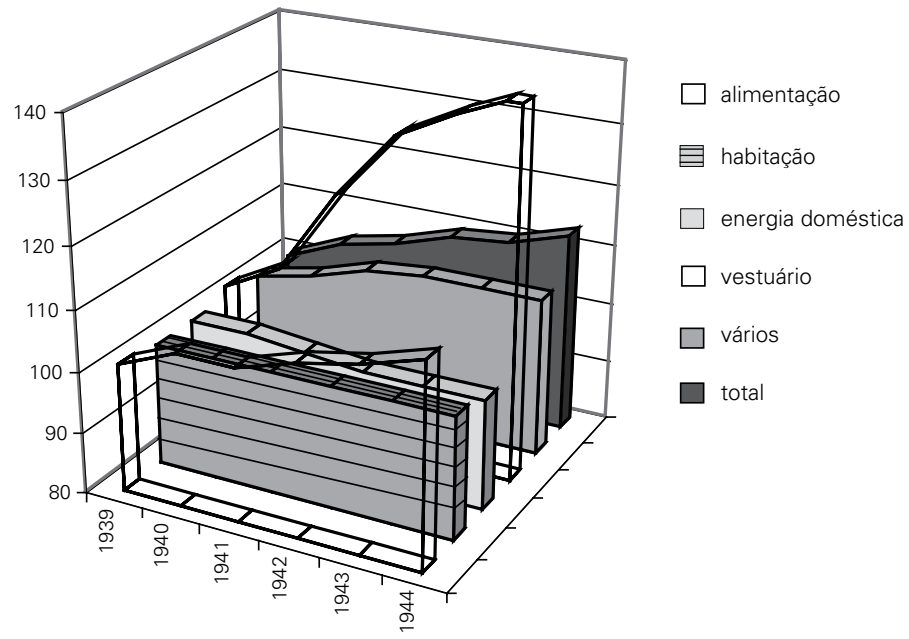

Fonte: Abelshauser (2000), p. 154.

1933 até o fim da Segunda Guerra Mundial. A base das evidências foi: (1) o desempenho na produção absoluta de armamento e no consumo per capita da classe trabalhadora. A queda no consumo após 1939 é esperada em se tratando de um período de guerra total, contundo, um nível razoável seria mantido até $1944 .^{8}$ (2) O desempenho na produtividade industrial: conforme Gráfico 2, a produtividade por trabalhador aumentou muito a partir de 1941 na produção de munição e se manteve na indústria de bens de consumo, com ligeiras oscilações. De fato, ela decaiu na indústria de base, especialmente em 1944, mas esse setor não era estratégico ou prioritário no fim do conflito. (3) O equilíbrio macroeconômico medido pela fraca pressão inflacionária, em que pesem preços controlados e o endividamento público crescente.

\section{CONSIDERAÇÕES FINAIS}

A seção anterior evidenciou dados que corroboram a hipótese de que a economia alemã foi eficiente na época do Terceiro Reich. Portanto, constatado o fato, cabe argumentar teoricamente a razão da eficiência dessa economia sob a égide do regime de Hitler. A primeira seção argumentou que tal eficiência foi alcançada operando-se um sistema econômico peculiar (economia de comando) com um grau re-

\footnotetext{
${ }^{8}$ Trabalhamos com valores agregados médios que não revelam a concentração do consumo em segmentos mais favorecidos da população, mesmo que tenhamos nos concentrado em dados que dizem respeito à classe trabalhadora alemã. É claro que situações dramáticas foram verificadas especialmente nos dois últimos anos do conflito: muitas famílias viviam permanentemente com fome e tinham que comer até comida estragada porque não tinham outra opção.
} 
lativamente descentralizado da economia, com certa liberdade para as lideranças setoriais encontrarem o melhor método de incrementarem a produção nos respectivos ramos de atuação. Não se sabe como poderia ter sido a produção alemã caso tivesse adotado o sistema totalmente centralizado: não há o contrafactual direto e, ademais, o planejamento central socialista, com a abolição da propriedade privada, estava fora dos contornos ideológicos do regime. Uma comparação interessante pode ser feita com o desempenho da economia da União Soviética na Segunda Guerra Mundial. O estudo de Harrison sobre a economia soviética fornece informações importantes. O Gráfico 9 mostra um indicador de produtividade da indústria de Stalin entre 1940 (ano anterior ao início do envolvimento na guerra) e 1944.

Gráfico 9: Produção por trabalhador na indústria soviética (\% de 1940)

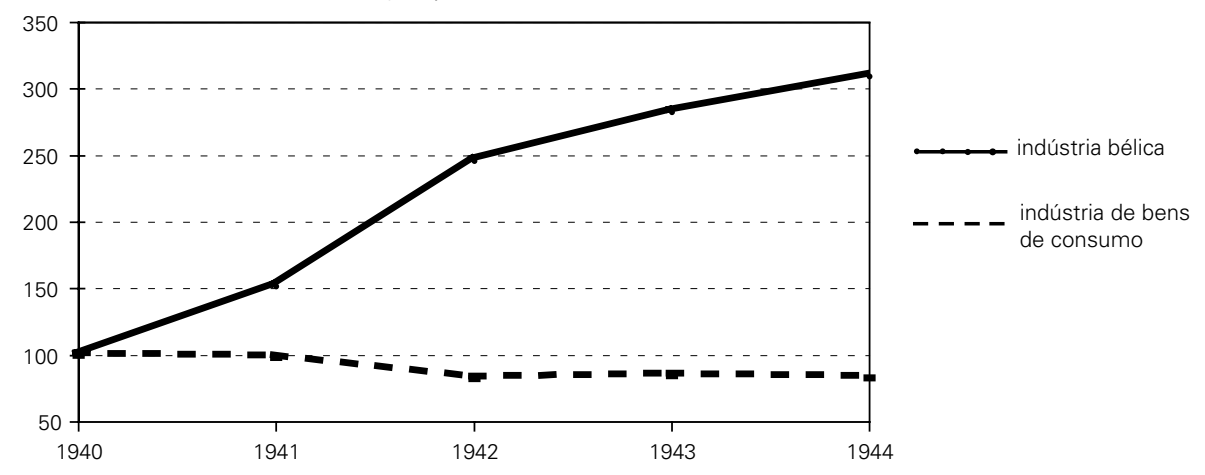

Fonte: cálculo do autor com base em informações sobre PNB setorial e população trabalhadora por setor em Harrison (2000), pp. 283 e 285.

Nota-se que, em relação à indústria bélica, a produtividade no socialismo soviético cresceu mais do que no caso da Alemanha nazista. Enquanto no primeiro caso avançou três vezes, neste último o aumento foi de 60\% (em relação a 1939). Este dado não é suficiente para alardear a superioridade na produção de guerra do socialismo. Dado o atraso da economia soviética, temos razões para acreditar que a sua produtividade no início da série viceja muito menor do que a alemã em 1939. Portanto, é mais fácil alcançar ganhos de produtividade quando se parte de um patamar mais baixo. Contudo, o dado mais sensível diz respeito à evolução comparativa da produtividade na indústria de bens de consumo. Enquanto na Alemanha em guerra esse setor teve ligeiro ganhos de produtividade, com oscilações (Gráfico 2), na Rússia Soviética e repúblicas satélites a produção por trabalhador caiu para $83 \%$ do nível inicial antes da guerra. Comparando-se os dois modelos, a economia alemã foi mais eficiente, pois também fez crescer a produtividade no setor industrial bélico e, adicionalmente, manteve e até incrementou um pouco a produtividade por trabalhador no setor da indústria de bens de consumo. 


\section{REFERÊNCIAS}

ABELSHAUSER, W. (2000) "Germany: guns, butter, and economic miracles". In: The Economics of World War II: Six Great Powers in International Comparison, Cambridge University Press, Cambridge, U.K., 2000, pp. 122-176.

EICHHOLTZ, D. (1985) Geschichte der Deutschen Kriegswirtschaft 1939-1945, vol. I, 1939-1941, Berlin.

GARVY, G. (1975) "Keynes and the Economic Activists of Pre-Hitler Germany," The Journal of Political Economy, Volume 83, Issue 2, pp. 391-405.

GRUNBERGER, R. (1970) A História da SS, Record, tradução de Ruy Jungmann, Rio de Janeiro e São Paulo, 1970.

HARRISON, M. (2000) “The Soviet Union: the defeated victor”. In: The Economics of World War II: Six Great Powers In International Comparison, Cambridge University Press, Cambridge, U.K., 2000, pp. 268-301.

KEYNES, J.M. (1991) Las consecuencias económicas de la Paz. Editorial Crítica, Madrid.

OVERY, R. (1996) The Penguin Historical Atlas of the Third Reich, Penguin Books Ltd, London, 1996.

PETZINA, D. (1968) “Autarkiepolitik im Dritten Reich. Der national-sozialistische Vierjahresplan”. Schrriftenreihe der Viertelsjahrshefte für Zeitgeschichte, vol. 16, Stuttgart. . (1997) Die Deutsche Wirtschaft in der Zwischenkriegszeit, Wiesbaden, 1977. . Abelshauser, W., Faust, A. (1978) “Materialien suz Statistik des Deutschen Reiches 1914-1945”, Sozialgeschichtliches Arbeitsbuch, vol.3, Munich.

ROCKWELL JUNIOR, L. H. (2003) “The Violence of Central Planning” http://www.lewrockwell. com/rockwell/centralplanning.html. Acesso em 23.09.2008.

ROCKOFF, H. (2000) "The United States: from ploughshares to swords". In: The Economics of World War II: Six Great Powers In International Comparison, Cambridge University Press, Cambridge, U.K., pp. 81-121.

TREVOR-ROPER, H. R. (1964) Os Últimos Dias De Hitler, Flamboyant, tradução de José B. Mari, São Paulo, $3^{\text {a }}$ ed., s.d.

UNITED STATES STRATEGIC BOMBING SURVEY. (145) Summary Report, European War, September 30, 1945, www.usaaf.net/.

VEILLON, D. (2004) Moda e Guerra: um Retrato da França Ocupada, Zahar Editor, tradução de André Telles, Rio de Janeiro.

ZAMAGNI, V. (2000) "Italy: how to lose the war and win the peace". In: The Economics of World War II: Six Great Powers In International Comparison, Cambridge University Press, Cambridge, U.K., pp. 177-223. 